\title{
ATIK KAZAN ALTI KÜLÜ VE POMZA ELEK ALTI ATIĞINDAN GEOPOLIMER YAPI MALZEMESİ ÜRETIMI
}

\author{
Neslihan DOĞAN-SAĞLAMTİMUR ${ }^{1}$ (ORCID: 0000-0001-6287-6268) * \\ Ahmet BILGIL ${ }^{2}$ (ORCID: 0000-0002-4196-0484)
}

\author{
${ }^{1}$ Çevre Mühendisliği Bölümü, Mühendislik Fakültesi, Niğde Ömer Halisdemir Üniversitesi, Niğde, Türkiye \\ ${ }^{2}$ İnşaat Mühendisliği Bölümü, Mühendislik Fakültesi, Niğde Ömer Halisdemir Üniversitesi, Niğde, Türkiye
}

Geliş / Received: 22.04 .2018 Kabul / Accepted: 08.06.2018

\begin{abstract}
ÖZ
Pomza üretimi sırasında elek altı olarak tarif edilen ince malzeme açı̆̆a çıkmaktadır ve atık malzeme durumundadır. Endüstrilerde kömür yakılması sonrası açığa çıkan kazan altı külü de depolanamaz bir atıktır. Bu çalışmada atık değerlendirme amacıyla bu iki tip atık, alkali bir aktivatör olan sodyum hidroksit $(\mathrm{NaOH})$ ile aktive edilerek geopolimer yapı malzemesi üretilmiştir. Deneysel çalışmada $\% 50$ atık kazan altı külü $(\mathrm{AKAK})+\% 50$ pomza elek altı atığı (PEAA) karıştırılarak oluşturulan atık dolgu malzemesine ağırlıkça \%10, 15, 20 ve 25 oranında $\mathrm{NaOH}$ ilave edilmiştir. Numuneler 70,100 ve $150{ }^{\circ} \mathrm{C}$ 'ye ayarlanan etüvde 24 saat süresince kürlenmiştir. Daha sonra numunelerin fiziksel ve mekanik özellikleri belirlenmiştir. Basınç dayanım değerlerine göre optimum sonuç, \%20 NaOH aktivatörlü $100{ }^{\circ} \mathrm{C}$ 'de kürlenen numunede $16,5 \mathrm{MPa}$ olarak bulunmuştur. Basınç dayanımlarında 28 günün sonunda 7 günlük değerlere göre \%6-9 oranında artış gözlenmiştir. Su emme ve porozite değerlerinde, diğer yapı malzemelerine benzer sonuçlar elde edilmiştir. Atık malzeme esaslı $\mathrm{NaOH}$ aktivatörlü numunelerden dış tesirlere dayanıklı geopolimer yapı malzemesi üretilebilmiştir.
\end{abstract}

Anahtar kelimeler: Atık yeniden kullanımı, geopolimer, kazan altı külü, pomza, yapı malzemesi

\section{GEOPOLYMER BUILDING MATERIAL PRODUCTION FROM WASTES OF BOTTOM ASH AND PUMICE}

\begin{abstract}
During pumice production, fine material that is stayed under the sieve is exposed as waste material. Bottom ash released into the air after burning coal in the industry is a non-deposit waste. In this study, for the aim of waste reuse, these two types of wastes were activated with sodium hydroxide $(\mathrm{NaOH})$, an alkaline activator, and geopolymer building material was produced. In the experimental study, $10 \%, 15 \%, 20 \%$ and $25 \% \mathrm{NaOH}$ were added to the filler material which was formed by mixing $50 \%$ waste bottom ash $+50 \%$ pumice waste to produce geopolymer samples. The samples were cured in the oven that was set at 70,100 and $150^{\circ} \mathrm{C}$ for 24 hours. Physical and mechanical properties of the samples were then determined. According to the compressive strength values, the optimum result was found to be $16.5 \mathrm{MPa}$ in the sample activated with $20 \% \mathrm{NaOH}$ cured at $100^{\circ} \mathrm{C}$. Compressive strength values were increased (6-9\%) in the samples at 28-day as compared to 7-day. Water absorption and porosity values were similar to those of other building materials. Geopolymer building material that is resistant to external influences can be produced from waste-based samples including $\mathrm{NaOH}$ activator.
\end{abstract}

Keywords: Waste reuse, geopolymer, bottom ash, pumice, building material

\footnotetext{
*Corresponding author / Sorumlu yazar. Tel.: +90 38822522 29; e-mail/e-posta: neslihandogansaglamtimur@gmail.com
} 


\section{GİRiș}

İnsan-yaşam standardını geliştirmek için- günümüzden yaklaşık 15000 yıl önce toprağı pişirerek malzeme üretmiş ve yapı teknolojisinde kullanmıştır. Günümüzde kullanılan yapı malzemeleri, endüstriyel hammaddelerden üretilmektedir. Endüstriyel hammadde tanımı kum ve çakıl, kireçtaşı, killer, zeolit, talk, vermikulit, sepiolit, diyatomit, grafit ve silikadan, manyezit, perlit, ponza, feldispat, mika, wollastonit, barit, florit gibi doğal taşlar ve gübreye kadar her çeşit mineral ve kayaçları kapsamaktadır [1].

Endüstriyel hammaddeler sınıfında yer alan malzemelerden biri olan pomza, magmanın yeryüzünde veya yeryüzüne oldukça yakın derinliklerde katılaşması sonucu oluşmuştur. Pomzanın kimyasal bileşiminde \%60-75 $\mathrm{SiO}_{2}, \%$ 13-17 $\mathrm{Al}_{2} \mathrm{O}_{3}, \%$ 1-3 $\mathrm{Fe}_{2} \mathrm{O}_{3}, \%$ 1-2 CaO, \%7-8 Na $\mathrm{Na}_{2} \mathrm{O}-\mathrm{K}_{2} \mathrm{O}$ eser miktarda $\mathrm{TiO}_{2}$ ve $\mathrm{SO}_{3}$ bulunmaktadır [2]. $\mathrm{Bu}$ hammadde, bol miktarda gaz boşluğu içerdiği ve bu boşluklar genellikle birbirleri ile bağlantılı olmadığından, suya atıldığı zaman dibe batmaz; pomza asit-ortaç bir bileşime sahip olmakla beraber kristal suyu içerir ve 1 sıtıldığında genleşmez. Dünya genelinde tespit edilen pomza rezervi 18 milyar ton civarındadır. Pomza yataklarının yer aldığı ülkelerin başında $\mathrm{ABD}$, Türkiye ve İtalya gelmektedir. Türkiye'deki pomza rezervi miktarı 7,4 milyar tondan daha fazladır. Buna göre Türkiye'deki pomza rezervi, Dünya pomza rezervinin neredeyse \%40’1 kadardır. Dünyada pomza rezervleri bakımından önemli bir yeri olan Türkiye, yaklaşı 10 farklı renk ve doku kalitesine sahip pomza çeşitleri ile oldukça yüksek bir pazar şansına sahiptir [2-4]. Üretim aşamasında, pomzanın granülometrik dağılımını düzenlemek için birçok ocaktaki eleme tesislerinden geçirilen malzemede önemli miktarda elek altı olarak tarif edilen ince malzeme açığa çıkmaktadır ve bir tür katı atıktır. Pomza elek altı atığı (PEAA) miktar olarak fazladır ve genellikle depo alanlarına gönderilir.

Sanayi tesislerinde, kömürün yakıt olarak kullanılmasından dolayı, bir tür endüstriyel katı atık olan kazan altı külü meydana gelmektedir. Tesisin işletilmesi sırasında oluşan atıkların başında gelen atık kazan altı külü (AKAK) çevreye oldukça zararlıdır ve depolama alanına gönderilmesi gerekir. Planlı ve sistemli bir çalışma ile depolama alanında biriken külün ve alçıtaşının, çimento, alçıpan üretimi gibi sanayi kollarına hammadde olarak satışı mümkündür. Satışı mümkün olmayan atıkların ise kül depolama alanlarında saklanması gerekir. Miktarı çok fazla olan, depolanması ve bertarafı sorun teşkil eden AKAK genellikle küresel değildir; 0,1-10 mm aralığında boyutta, belirgin koyu gri renkte ve gözenekli yapıdadır. AKAK çoğunlukla silikat, karbonat, alüminat, demir ve çeşitli metal ve metalloitlerden oluşur [5-11].

Pomza gözenekli yapısı, hafifliği, yüksek izolasyon etkileri, atmosferik şartlara karşı direnci ve yüksek puzzolanik aktivitesi sebebiyle insanoğlunun eski çağlardan beri kullandığı yapı malzemelerinden birisi durumundadır [3]. Pomza, Hıristiyanlıktan çok önce, Yunanlılar ve daha sonra da Romalılar tarafindan kullanılmıştır. Amerika Birleşik Devletleri (ABD)'nin California eyaletinde kalıplaştırılmış pomza 1851 yılından beri inşaatlarda kullanılmaktadır. ABD'de hafif, yalıtımlı-beton agregası olarak 1935'te kullanılmaya başlanmış ve kullanım oranı bundan sonra da düzenli bir artış göstermiştir. Almanya, II. Dünya Savaşı'ndan önce hafif bina yapım ünitelerinde güçlü bir üretici ve ihracatçı olmuştur. M.S. IV. yüzyıldan XIX. yüzyıla kadar Almanya'nın Ren Bölgesindeki şehirlerde pomza kullanılmaya başlandığı gözlenmiştir [12]. Pomzanın ilk kullanıldığ bölgelerden biri de Türkiye'den Van Gölü Havzası'dır. Urartular döneminde (M.Ö. 900-600) konutlarda ve gıdaların bozulmasını önlemek amacıyla gıdaların muhafaza edildiği depolarda izolasyon malzemesi olarak pomza kullanılmıştır [13].

Son yıllarda hafif yapı malzemelerine verilen önemin giderek artmasına paralel olarak pomza, düşük birim hacim ağırlığı, 1sı ve ses izolasyonu, akustik, iklimlendirme, kolay sıva tutma, deprem yük ve davranışları karşısındaki elastikiyet ve alternatiflerine göre daha ekonomik oluşu gibi üstün özelliklerinden dolayı, inşaat ve yapı endüstrisinde geniş bir kullanım alanı bulmuştur [3]. Yeryüzünde en yaygın olarak bulunan ve kullanımı en geniş olan asidik pomza beyaz ve kirli renkte, bazik pomza ise siyahımsı renktedir. Asidik karakterli pomzalarda silis oranı daha yüksek olduğundan dolayı inşaat sektöründe yaygın kullanım alanı vardır. Pomzalı beton normal betona göre deprem yüklerine karşı daha elastik davranış gösterebilmekte ve donma durumundan etkilenmemektedir $[12,14]$.

AKAK'ın beton özellikleri üzerine etkisini araştıran Bai vd. [15] \%30’dan \%100'e kadar çeşitli oranlarda AKAK'` doğal kum ile yer değiştirmişlerdir. İnce agrega olarak AKAK kullanılan betonun dayanım ve büzülme özelliklerini incelemiş, \%30 oranında AKAK'ın ince agrega yerine kullanılabilir olduğu sonucuna ulaşmışlardır. Yüksel vd. [16], ince agrega olarak kullanılan AKAK'ın betonun porozitesini arttırdığını ve AKAK kullanımı ile dayanıklı beton üretiminin mümkün olduğunu belirtmişlerdir. Nataraj vd. [17], AKAK'ın beton içinde kullanımını, betonda agrega kullanımına alternatif olarak önermişlerdir. Jayaranjan vd. [11], literatür bilgisine dayanarak göreceli olarak yüksek özgül ağırlığa sahip (1,9-3,0) AKAK'ların mühendislik uygulamalarında kullanılması gerektiğini belirtmişlerdir. Wongkeo ve Chaipanich [18], AKAK ve silika dumanı ile yapılan hafif yapı malzemesi üzerine basınç dayanım, mikro yapı ve termal analizler yapmış ve silika dumanı karışıma eklendiğinde AKAK'lı hafif yapı malzemesinin basınç dayanımının arttığını bulmuşlardır. \%5 silika dumanı ve \%20 KAK karışımı kullanıldığında Portland çimento kontrol grubundan daha yüksek basınç dayanıma 
ulaşıldığını belirlemişlerdir. Doğan-Sağlamtimur vd. [8] yaptıkları çalışmada pomza, CEM I ve CEM II çimento, iki endüstriyel firma (Göknur A.Ş. ve Bor Şeker Fabrikası) ve bir termik santralden alınan (ISSKEN A.Ş. Sugözü Termik Santrali) AKAK ve atık uçucu kül kullanılarak dayanıklı hafif yapı malzemeleri üretilmiş, fizikselmekanik özellikleri belirlenmiştir. Bu pomza-kül esaslı çimento bağlayıcılı yapı malzemelerinden basınç dayanım değeri en iyi çıkan \%50 BorAKAK+CEM II karışımlı numune olarak bulunmuştur.

Günümüzde inşaat sektöründe en çok kullanılan bağlayıcı malzeme çimentodur [19]. Çimento sektörü, Dünya çapında toplam antropojenik (insan kaynaklı) $\mathrm{CO}_{2}$ emisyonunun yaklaşık \%5-8'inden sorumludur. Ĕger üretimde fosil yakıt kullanılmışsa ve herhangi iyileştirici bir yöntem uygulanmadıysa 1 ton klinker üretimi sonucu 1 ton $\mathrm{CO}_{2}$ emisyonu açığa çıktığı genel olarak kabul edilir [20]. Ayrıca çimento, yüksek sıcaklıkta (14001500 oC) üretildiği için önemli ölçüde enerji tüketimi söz konusudur ve bu yüksek enerji ihtiyacı nedeniyle yüksek maliyetlerle elde edilmektedir. Çimentosuz bir teknoloji olan geopolimerin kullanılması ile çimento üretiminde ortaya çıkan $\mathrm{CO}_{2}$ miktarının azalması sonucunda çevreye olan zararlı etki azalmış olacaktır. Ayrıca bu tip çimentoların üretiminde enerji ihtiyacı azalacağından önemli ölçüde enerji tasarrufu sağlayacaktır [19].

Geopolimer, ilk önce yangınlara karşı malzeme direncini artırmak için organik 1sıyla sertleşen polimerlere alternatif olarak geliştirilmiştir. Geçen yıllar boyunca, geopolimerler ve geopolimer kompozitler çok çeşitli düşük ve yüksek teknoloji uygulamaları için kullanılmıştır [21]. Geopolimerizasyon, katı alüminosilikat hammaddesini (tozları) ve alkali metal silikat çözümlerini, geopolimer veya inorganik polimerler olarak adlandırılan üç boyutlu polimerik yapılar ile karakterize edilen yeni malzemeler üretmek için kullanabilen yenilikçi bir teknolojidir [22]. Metakaolin, kireç, uçucu kül, yüksek firın cürufu gibi doğal ve endüstriyel atık malzemelerin alkalilerle aktivasyonu sonucu geopolimer elde edilebilmektedir [23].

Pomza esaslı çimento bağlayıcılı yapı malzemesinde çimentodan kaynaklanan agrega reaktivitesinin oluşması, termal iletkenlik ve birim hacim ağırlığının $0,7 \mathrm{~g} / \mathrm{cm}^{3}$ ten aşağılara çekilememesi önemli sorunlar oluşturmaktadır. Bu nedenle pomza için yeni bir bağlayıcı aranmış ve çimento yerine bazı kimyasalların bağlayıcı olarak kullanılması yoluna gidilmiştir. Çimentolu yapı malzemelerine alternatif malzemeler bulmak güncel araştırma konuları arasında yer almaktadır. Bu çalışmalara, literatürdeki birçok çalışmanın yanı sıra, pomza esaslı polimer bağlayıcılı hafif beton blok üretimi örnek olarak verilebilir. Özellikle geopolimer esaslı yapı malzemesi üretimine aşırı ilgi duyulmaktadır [24-26].

Her yıl ortaya çıkan ve zaten var olan çevre felaketine göz ardı edilmeyecek oranda katkıda bulunan milyonlarca ton yeni atığın, ancak inşaat sektörü gibi çok büyük hacimlerde tüketim yapan sektörlerde değerlendirilmesi anlamlı olabilmektedir. Atıkların yapı malzemesi olarak değerlendirilmesi, böylece atık stok miktarlarının artışının önlenmesi de birçok bilimsel araştırmanın ana hedeflerinden olmuştur [6, 27]. Bu çalışmada katı atıklar olan PEAA ve AKAK, insanın en temel ihtiyacı olan barınma ihtiyacını karşılayan, yarattığı katma değer ve istihdam olanaklarıyla Dünya ve Türkiye ekonomileri için çoğu zaman bir kaldıraç görevini üstlenen, yıllık büyüme oranı \%7,1 ve Gayri Safi Yurtiçi Hasıla içerisindeki payı \%6 olması [28] nedenleriyle, inşaat sektöründe kullanılmak üzere değerlendirilmişlerdir. Yapı malzemeleri piyasa değeri fazla olan, malzeme olarak üstünlükleri bulunan, yüksek dayanım gösteren ve sudan sonra kişi başına en çok kullanılan maddelerden birisidir. Bu çalışmada \%50 PEAA+\%50 AKAK ve bunların toplam ağırlı̆̆ının \%10, 15, 20 ve 25 oranlarında sodyum hidroksit $(\mathrm{NaOH}$, alkali aktivatör olarak) kullanılarak geopolimer yapı malzemeleri üretilmiş, fiziksel ve mekanik özellikleri belirlenmiştir.

\section{MATERYAL VE METOT}

\subsection{Materyal}

$\mathrm{Bu}$ çalışmanın birinci materyali olan PEAA, Niğde ili Altunhisar bölgesinden temin edilmiştir. Bu bölgede yapılan arazi çalışmaları neticesinde, pomza görünen rezervinin yaklaşık 250 milyon ton olduğu söylenebilir. Daha önceleri işletilen bölgelerde halihazırda ocak işletmeciliği yapılmamaktadır ve aşırı miktarda atık pomza tozu bulunmaktadır. Çalışmada Altunhisar bölgesindeki görünen rezervlerin farklı bölgelerinden alınan numuneler harmanlanarak yı̆̆ın oluşturulmuş ve Niğde Ömer Halisdemir Üniversitesi Mühendislik Fakültesi İnşaat Mühendisliği Bölümü laboratuvarına getirilerek fiziksel ve kimyasal özellikleri belirlenip Tablo 1'de özetlenmiştir. Bu malzeme 0,5 mm kare gözlü elekten elenmiş ve elek altına geçen kısım (PEAA), çalışmanın materyalini oluşturmuştur. Materyalin granülometrik dağılımı belirlenmiş ve Şekil 1'de grafik halinde sunulmuştur.

Çalışmanın ikinci materyali ise AKAK olup Bor Şeker Fabrikası'ndan (Niğde, Türkiye) temin edilmiştir. Bu atığın miktarı, yıllık yaklaşık 17000-19000 tondur. Bu malzemenin de kimyasal analizi yapılarak Tablo 1'de verilmiştir. Bu malzeme de 0,5 mm kare gözlü elekten elenmiş ve granülometrik dağılımı belirlenerek Şekil 1'de grafik halinde sunulmuştur. 
Tablo 1. Bu çalışmada kullanılan materyallerin fiziksel ve kimyasal özellikleri

\begin{tabular}{|c|c|c|c|c|c|c|c|c|c|}
\hline Kimyasal & $\mathrm{SiO}_{2}$ & $\mathrm{Al}_{2} \mathrm{O}_{3}$ & $\mathrm{Fe}_{2} \mathrm{O}_{3}$ & $\mathrm{CaO}$ & MgO & $\mathrm{Na}_{2} \mathrm{O}$ & $\mathbf{K}_{2} \mathbf{O}$ & $\mathrm{SO}_{3}$ & Diğer \\
\hline \multicolumn{10}{|c|}{ PEAA } \\
\hline Miktar (\%) & 52,97 & 11,38 & 6,77 & 13,40 & 1,90 & 3,83 & 2,39 & 0,49 & 3,87 \\
\hline \multicolumn{10}{|c|}{$\begin{array}{l}\text { Etüv kurusu sonrası sıkışı birim hacim ağırlı̆̆ }(\mathrm{BHA}): 1,47 \mathrm{~g} / \mathrm{cm}^{3} \\
\text { Etüv kurusu sonrası geş̧ek BHA : } 1,27 \mathrm{~g} / \mathrm{cm}^{3} \\
\text { Kızdırma kayb1 : \%5,65 }\end{array}$} \\
\hline \multicolumn{10}{|c|}{ AKAK } \\
\hline Miktar (\%) & 27,98 & 10,30 & - & 7,97 & 1,64 & 0,46 & 0,82 & 10,35 & 15,77 \\
\hline
\end{tabular}

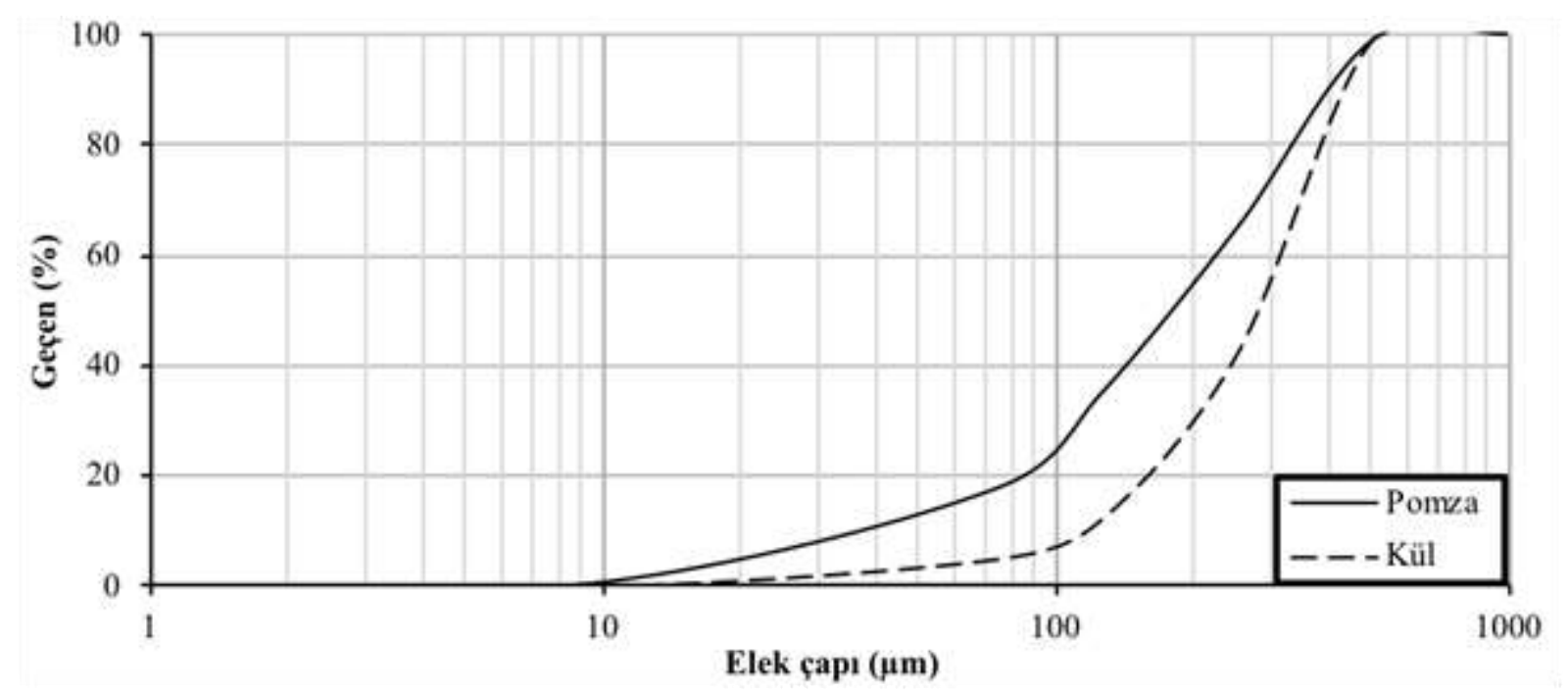

Şekil 1. Çalışmada kullanılan PEAA ve AKAK'ın granülometrik dağılımı

\subsection{Alkali Aktivatör}

Pellet/Payet halindeki katı NaOH (\%99 saflıkta ve BHA's1 $1,11 \mathrm{~g} / \mathrm{cm} 3$ olan) $1 \mathrm{~L}$ suda (Niğde Ömer Halisdemir Üniversitesi çeşme suyu) çözülerek 12,5 M sıvı NaOH çözeltisi hazırlanmıştır.

\subsection{Yöntem}

Bu çalışmada, her iki atık malzeme $0,5 \mathrm{~mm}$ kare gözlü elekten ayrı ayrı elendikten sonra \%50 PEAA+\%50 AKAK olacak şekilde birleştirilmiş, homojen hale gelene kadar karıştırılmıştır. Numune setlerindeki karışım oranları ağırlık esasına göre gerçekleştirilmiș olup $\mathrm{NaOH}$ miktarı, pomza ağırlığının \%10, 15, 20 ve 25 oranı olarak kabul edilmiştir. Numunelerin karıştırılması masa tipi mikserde yapılmış, önce $12,5 \mathrm{M} \mathrm{NaOH}$ alkali çözelti olarak konmuş, daha sonra atık malzemeler ilave edilerek düşük devirde 60 saniye karıştırılmıştır. Numune üretimi için 40x40x160 mm boyutlarındaki prizmatik çimento harç kalıpları kullanılmış ve numuneler kalıplara şişleme çubuğu ile sıkıştırılarak yerleştirilmiştir. İhtiyaca göre su ilave edilerek hamur kıvamına getirilmiş ve 3 dakika yüksek devirde karıştırılması yeterli görülmüştür. Çalışmada üretilen geopolimer numunelerin karışım miktarları ve kürleme sıcaklıkları Tablo 2'de özetlenmiştir. 
Tablo 2. Atık malzeme (PEAA ve AKAK) dolgulu NAOH aktivatörlü geopolimer numunelerin karışım miktarları

\begin{tabular}{|c|c|c|c|c|c|c|c|c|}
\hline 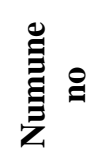 & $\sum_{1}^{\infty}$ & 这 & 矛 & 旅 & 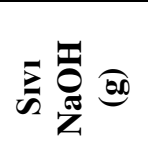 & क节 & 莺 & 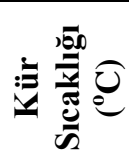 \\
\hline P1 & 500 & 500 & 10 & 100 & 200 & 180 & 6 & \multirow{4}{*}{70} \\
\hline $\mathrm{P} 2$ & 500 & 500 & 15 & 150 & 300 & 95 & 6 & \\
\hline P3 & 500 & 500 & 20 & 200 & 400 & 25 & 6 & \\
\hline P4 & 500 & 500 & 25 & 250 & 500 & -- & 6 & \\
\hline P5 & 500 & 500 & 10 & 100 & 200 & 180 & 6 & \multirow{4}{*}{100} \\
\hline P6 & 500 & 500 & 15 & 150 & 300 & 95 & 6 & \\
\hline P7 & 500 & 500 & 20 & 200 & 400 & 25 & 6 & \\
\hline P8 & 500 & 500 & 25 & 250 & 500 & -- & 6 & \\
\hline P9 & 500 & 500 & 10 & 100 & 200 & 180 & 6 & \multirow{4}{*}{150} \\
\hline P10 & 500 & 500 & 15 & 150 & 300 & 95 & 6 & \\
\hline P11 & 500 & 500 & 20 & 200 & 400 & 25 & 6 & \\
\hline P12 & 500 & 500 & 25 & 250 & 500 & -- & 6 & \\
\hline
\end{tabular}

Numuneler deney kalıbına yerleştirildikten sonra 70,100 ve $150{ }^{\circ} \mathrm{C}$ kür sıcaklığına göre takım oluşturularak pişirme firınında 24 saat süre ile kürlenmiş, daha sonra kalıptan sökülerek laboratuvar ortamı sıcaklı̆ı̆ında boyutları ve ağırlıkları ölçülmüştür. $\mathrm{Bu}$ ölçümlerden numunelerin kürleme esnasındaki büzülme miktarı belirlenmiştir. Ancak kayda değer olabilecek bir büzülme tespit edilmemiştir. Oda sıcaklığında bekletilen numunelerde 7 ve 28. günün sonunda eğilme ve basınç dayanım testleri gerçekleştirilmiştir. Geopolimer numuneler öncelikle eğilme dayanımı testine tabi tutulmuş, ancak eğilme testinde çekme gerilmelerini hesaplayabilecek değerlere ulaşılamamıştır. Eğilme testinde ikiye bölünmüş numunelerin alt ve üst yüzeyine 40x40 mm plakalar yerleştirilerek her iki numunenin de basınç gerilmeleri belirlenerek aritmetik ortalama değerleri alınmışıtır. Bu dayanım değerleri TS EN 1015-11 [29] standardına uygun olarak belirlenmiştir. 28 gün ortam sıcaklığında bekletildikten sonra numunelerde su emme ve porozite değerleri belirlenmiştir.

\section{BULGULAR VE TARTIŞMA}

$\mathrm{Bu}$ çalışmada her deney için üçer adet numune kullanılarak elde edilen sonuçların aritmetik ortalama değerleri alınmıştır. Üretilen geopolimer yapı malzemesinin fiziksel ve mekanik özellikleri, Tablo 3 'te özetlenmiş ve Şekil 2-5'te grafik olarak sunulmuştur.

Şekil 2'de görüldüğü gibi, PEAA ve AKAK dolgulu alkali aktivatör ile üretilen numunelerin 7 gün sonras1 basınç dayanımları için optimum değer, $100 \mathrm{oC}$ 'de kürlenen $\% 20 \mathrm{NaOH}$ karışım oranı içeren numunelerden elde edilmiş̧ir. \%25 NaOH karışım oranına sahip numunelerde basınç dayanım değerleri yüksek (yaklaşık \%2,5) çıksa da, ekonomik faktörler dikkate alındığında bu artışın ihmal edilebilecek düzeyde olduğu görülmüsstür. 28 günlük numunelerde de -7 gün sonrası elde edilen basınç dayanım değerlerinde olduğu gibi- optimum değerler, $100{ }^{\circ} \mathrm{C}^{\prime}$ de kürlenen $\% 20 \mathrm{NaOH}$ karışım oranı içeren numunelerden elde edilmiştir. $\% 20$ karışım oranına sahip numunelerde elde edilen basınç dayanım değerleri, \%25 karışım oranına sahip numunelerden elde edilen değerlerden $\% 3,5$ daha düşük bulunmuştur.

Oda koşulunda 7 ve 28 gün kürlenme sürelerine göre, bekleme (kür) süresi uzadıkça reaksiyonun devam ettiği sonucuna ulaşılmıştır. 28 günden daha uzun kürlenme sürelerinde malzeme performansının nasıl bir seyir izleyeceği bu çalışmada dikkate alınmamıştır. 28 günlük kürlenme süresinde basınç gerilme değerleri bütün kürlenme sıcaklıklarında birbirine yakın artış eğilimindedir. 7 günlük numunelere göre 28 günün sonunda $\% 6-9$ oranında artış göstermiştir (Tablo 3). 
Tablo 3. Atık malzeme (PEAA ve AKAK) dolgulu NAOH aktivatörlü geopolimer yapı malzemelerinin fiziksel ve mekanik özellikleri

\begin{tabular}{|c|c|c|c|c|c|c|c|c|}
\hline$\stackrel{\Xi}{\Xi}$ & $\mathbb{x}^{0}$ & 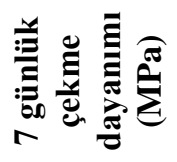 & 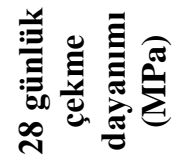 & 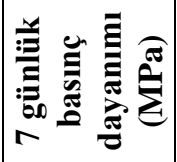 & 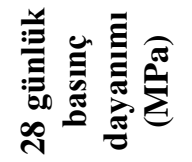 & 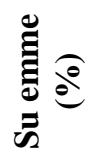 & 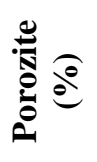 & 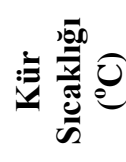 \\
\hline P1 & 1,56 & - & - & 5,2 & 6,2 & 38 & 36 & \multirow{4}{*}{70} \\
\hline P2 & 1,61 & - & - & 8,6 & 9,1 & 36 & 37 & \\
\hline P3 & 1,67 & - & - & 13,2 & 14,8 & 33 & 40 & \\
\hline P4 & 1,69 & - & - & 14,2 & 15,3 & 29 & 42 & \\
\hline P5 & 1,54 & - & - & 6,3 & 7,7 & 35 & 38 & \multirow{4}{*}{100} \\
\hline P6 & 1,61 & - & - & 9,2 & 10,2 & 34 & 40 & \\
\hline P7 & 1,66 & - & - & 15,2 & 16,5 & 31 & 41 & \\
\hline P8 & 1,70 & - & - & 15,6 & 17,1 & 27 & 44 & \\
\hline P9 & 1,56 & - & - & 6,1 & 7,2 & 37 & 38 & \multirow{4}{*}{150} \\
\hline P10 & 1,60 & - & - & 8,9 & 9,6 & 35 & 41 & \\
\hline P11 & 1,68 & - & - & 14,6 & 15,7 & 30 & 43 & \\
\hline P12 & 1,71 & - & - & 15,5 & 16,1 & 26 & 45 & \\
\hline
\end{tabular}
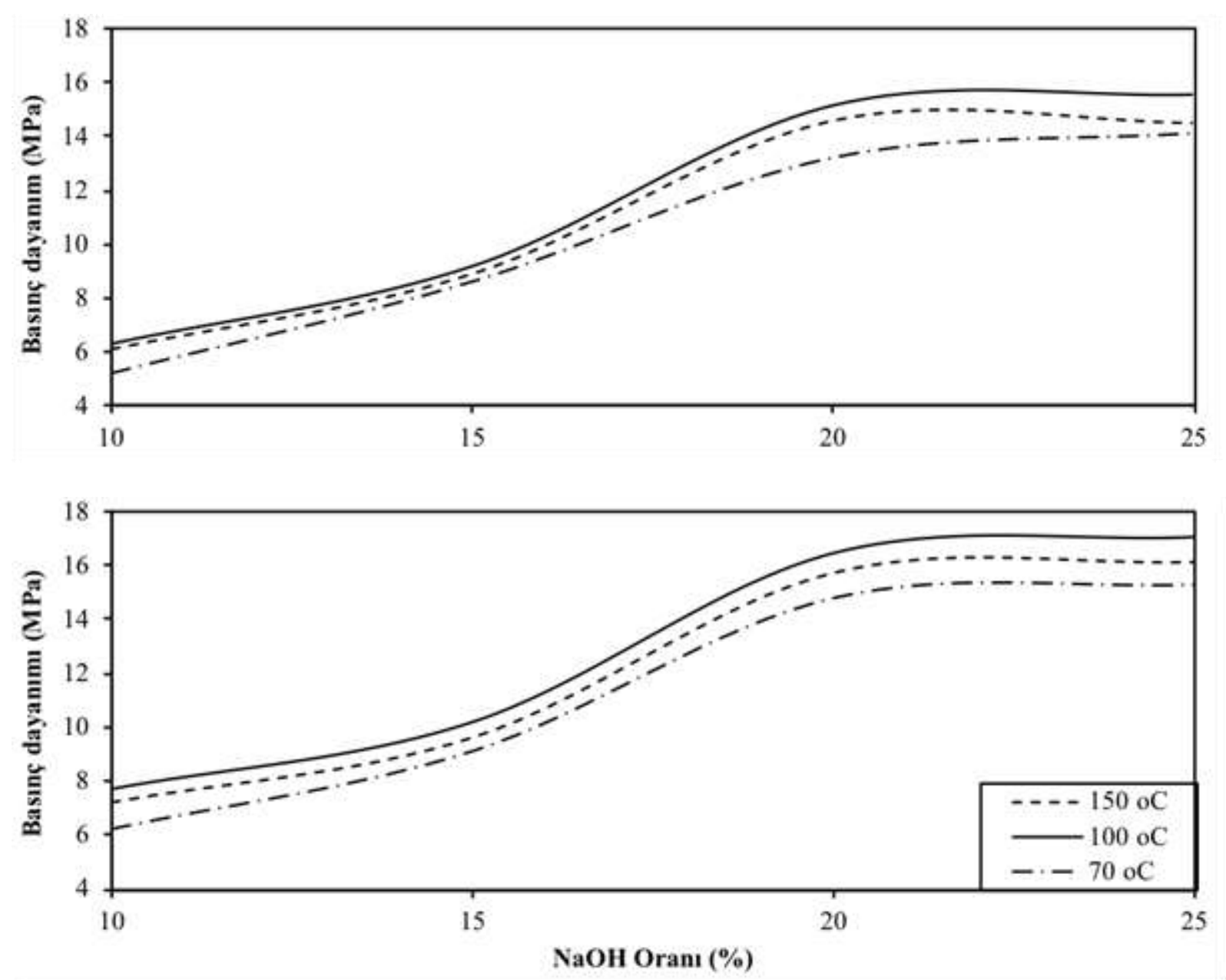

Şekil 2. PEAA ve AKAK dolgulu NAOH aktivatörlü geopolimer yapı malzemelerinin 7 günlük (üstte) ve 28 günlük (altta) basınç dayanım değerlerinin değişimi 


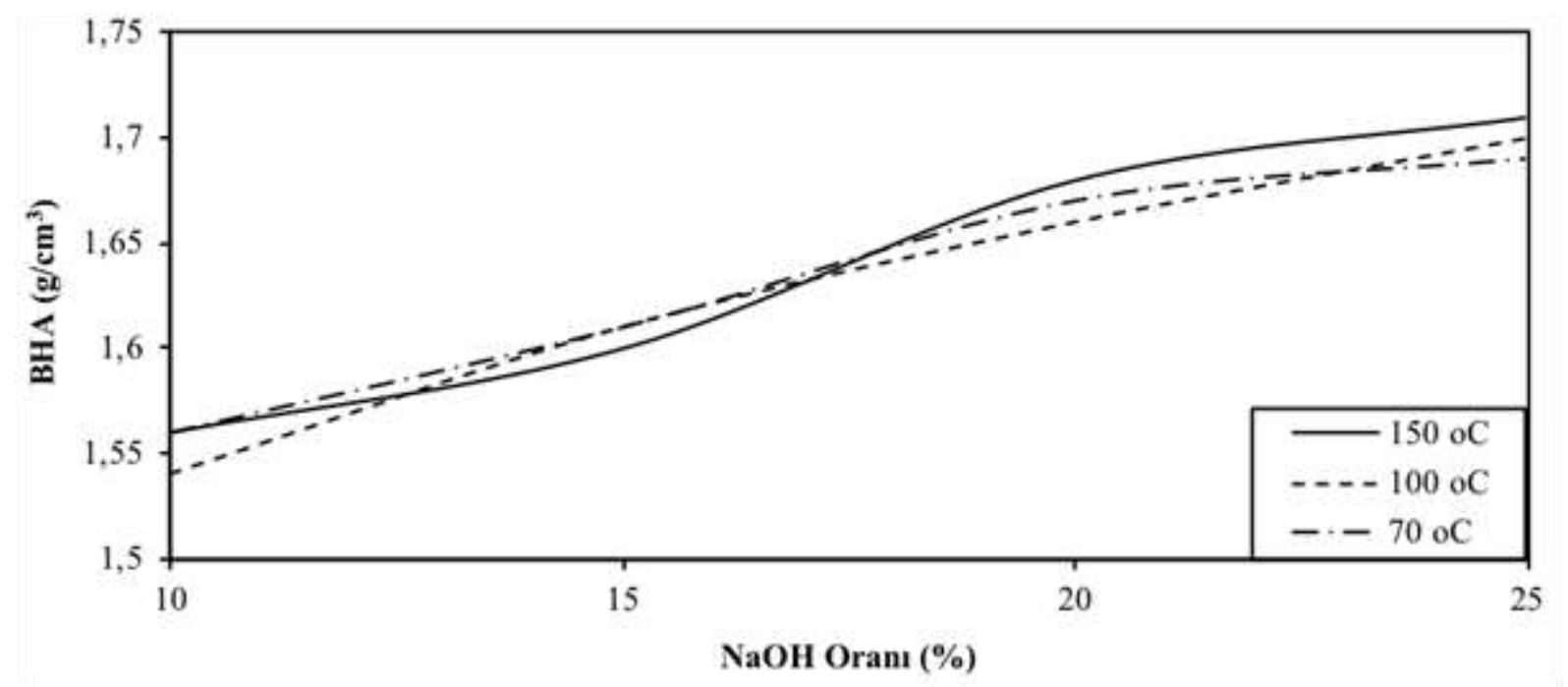

Şekil 3. PEAA ve AKAK dolgulu NAOH aktivatörlü geopolimer yapı malzemelerinin 28 gün kür süresi sonu BHA değerlerinin değişimi

Elde edilen numunelerin BHA'larının belirlenmesi için etüvden çıktıktan sonra (24 saat kür sonu) ağırlıkları kaydedilmiştir. Aynı zamanda laboratuvar ortamı şartlarında kürlemeye devam ettiği sürede 7 ve 28 günlük numune ağırlıkları da belirlenmiştir. $150{ }^{\circ} \mathrm{C}$ 'de kürlenen numunelerde etüv kür sonu ile 28 günlük kür sonu arasında -havanın neminin etkisiyle- ortalama \%1'lik ağırlık artışı gözlenmiştir. $70{ }^{\circ} \mathrm{C}$ 'de kürlenen numunelerde ise \%1'lik ağırlık kaybı olduğu görülmüştür. Bunun nedeninin, etüvde 24 saatlik kürleme süresinde, malzemenin bünyesindeki karışım suyunun tamamen atılamayışı olduğu kanaatine varılmıştır. Çalışmada 1 ve 7 günlük BHA değerleri değerlendirilmeye alınmamış, sadece 28 günün sonunda hesaplanan BHA dikkate alınarak Tablo 3'de verilmiş ve Şekil 3'te grafik haline dönüştürülmüştür. Grafikten de görüldüğü gibi numunelerin BHA değerleri beklenenden daha yüksek çıkmıştır; karışıma giren $\mathrm{NaOH}$ oranı arttıkça buna paralel olarak BHA değerleri de yükselmektedir.

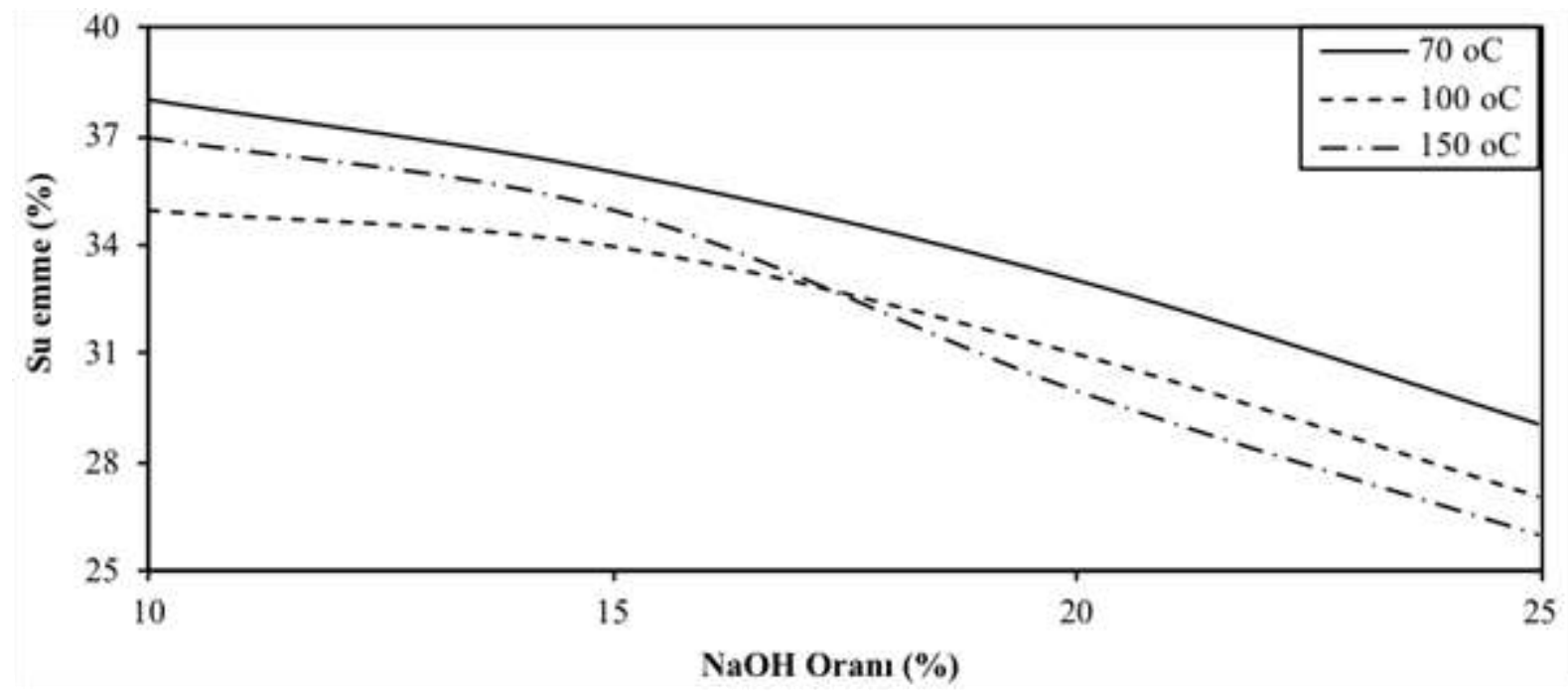

Şekil 4. PEAA ve AKAK dolgulu NAOH aktivatörlü geopolimer yapı malzemelerinin 28 gün kür süresi sonu su emme değerlerinin değişimi

Şekil 4'te numunelerin su emme değerleri grafik haline dönüştürülmüştür. Su emme testi ile $\mathrm{NaOH}$ aktivatörlü üretilen numunelerin dış tesirlere dayanımının belirlenmesi hedeflenmiştir. Numunelerin su içinde bekletilmesi esnasında $70{ }^{\circ} \mathrm{C}$ 'de kürlenen numunelerin yüzeyinde film tabakası şeklinde etkilenme gözlenmiş, diğer sıcaklıklarda kürlenen numunelerde bu durum gözlenmemiştir. Su emme değerleri karışıma giren aktivatör oranına göre düşüş göstermiştir. Bunun nedeninin silikat ve alüminatların reaksiyona girerek 
boşlukların izole edilmesi olduğu kanaatine varılmıştır. Doğal olarak $\mathrm{NaOH}$ arttıkça silikat ve alüminatlar ile daha fazla bağ oluşumu gözlenebilir. Ancak belli bir oranı geçtiği zaman alkali aktivatörün bağ oluşturması için özellikle hammaddedeki alüminyum oksit oranının yüksek olması gerekmektedir.

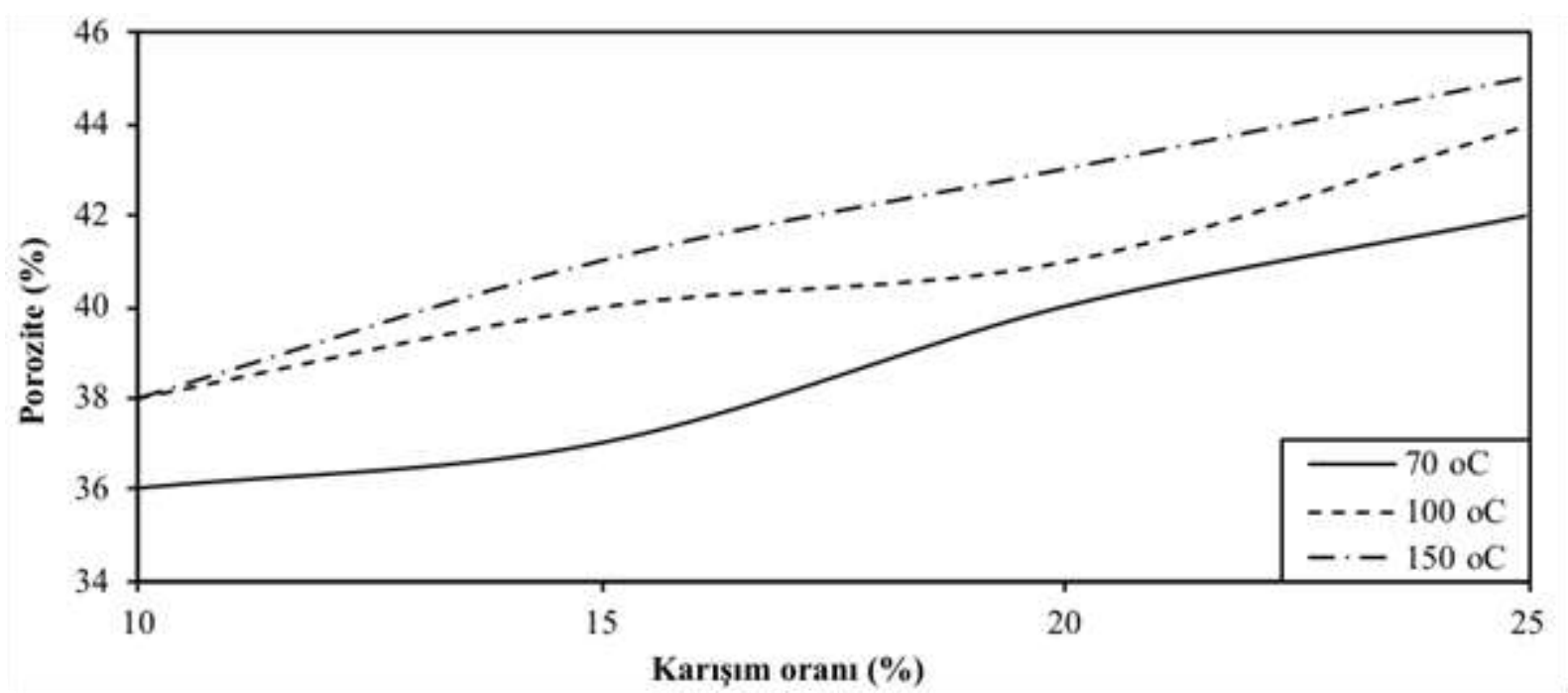

Şekil 5. PEAA ve AKAK dolgulu NAOH aktivatörlü geopolimer yapı malzemelerinin 28 gün kür süresi sonu porozite değerlerinin değişimi

$\mathrm{Bu}$ çalışmada üretilen geopolimer malzemelerin porozite değerleri Şekil 5'te grafikleştirilmiştir. Numunelerin hacimce su emme değerleri, poroziteyi vermektedir. Elde edilen sonuçlara göre alkali aktivatör oranı artıkça poroz bir malzeme üretildiği görülmüştür. Poroziteye en fazla sahip olan numuneler, $150{ }^{\circ} \mathrm{C}$ sıcaklıkta kürlenen numuneler olmuştur. Bunun nedeni, yüksek derecelerde kürleme yapıldığı takdirde -hızlı bir reaksiyon göstererek ve bünyesindeki suyun hızla buharlaşmasıyla- buharlaşma yolunun açmış olduğu boşlukların fazlalı̆̆ıdır.

\section{SONUÇLAR}

$\mathrm{Bu}$ çalışmada, PEAA ve AKAK karışımı NaOH ile aktive edilerek yapı teknolojisinde kullanılmak üzere geopolimer beton üretilmiştir. Dolgu olarak kullanılan atık malzeme -ağırlığının \%10, 15, 20 ve 25'i oranlarında $\mathrm{NaOH}$ ilave edilerek- aktive edilmiş, 40x40x160 mm boyutlarında numuneler üretilmiştir. Bu çalışmadan elde edilen sonuçlar;

1- Numuneler 24 saat süresince 70,100 ve $150{ }^{\circ} \mathrm{C}$ 'deki etüv sıcaklıklarında bekletilerek kürlenmiştir. 7 ve 28 günlük basınç dayanım değerleri ölçülmüştür. Basınç dayanım değerlerine göre optimum sonuç, $100{ }^{\circ} \mathrm{C}$ 'de kürlenen \%20 NaOH aktivatörlü numunelerde elde edilmiştir.

2- Basınç dayanım değerleri -7 günlük numunelere göre- 28 günün sonunda \%6-9 oranında artmıştır. Bu eğilim, bütün kürlenme sıcaklıklarında birbirine benzerlik göstermiştir.

3- Etüv kür sonu ile 28 günlük kür sonu arasında ortalama $150{ }^{\circ} \mathrm{C}$ 'de kürlenen numunelerde \%1'lik ağırlık artış1 olurken $70{ }^{\circ} \mathrm{C}$ 'de kürlenen numunelerde \%1'lik ağırlık kaybı olduğu görülmüştür.

4- Su emme ve porozite değerlerini belirlemek için yapılan çalışmalarda, $70^{\circ} \mathrm{C}$ 'de kürlenen numunelerin sudan az da olsa etkilendiği görülmüştür. Porozite ve su emme değerleri açısından geopolimer yapı malzemelerinde, çimento esaslı malzemelerin değerlerine benzer sonuçlar elde edilmiştir.

5- Geopolimer yapı malzemesi üretiminde PEAA ve AKAK dolgu miktarı arttırılıp kimyasal aktivatör miktarı azaltıldığında, basınç dayanım değerleri azalma eğilimi göstermektedir. Benzer sonuçlar, Binici vd. [30] ve Top ve Vapur [31] tarafından yapılan çalışmalarda üretilen geopolimer yapı malzemelerinde de elde edilmiştir.

$\mathrm{Bu}$ çalışmada PEAA ve AKAK esaslı $\mathrm{NaOH}$ bağlayıcılı, dış tesirlere dayanıklı, 2,5 MPa'dan fazla basınç dayanımına sahip olması nedeniyle duvar yapımına uygun, BHA'sının 1,6 g/cm ${ }^{3}$ 'den daha düşük olması sayesinde hafif yapı malzemesi olabilecek nitelikte geopolimer malzeme üretilmiştir. Dünyada pomza rezervi bakımından önemli bir yeri olan Türkiye, yaklaşık on farklı renk ve doku kalitesine sahip pomza çeşitleri ile oldukça yüksek bir pazar şansına sahiptir. Endüstrilerde kömür yakılması sonucu açığa çıkan AKAK'ın 
miktarının fazla olması nedeniyle depolanma sorunları bulunmaktadır ve çevresel problemlere yol açar. Bu çalışmada yapılan üretimle Türkiye'deki PEAA ve AKAK, yapı malzemesi üretiminde kullanılarak ve etkinliği artırılarak, inşaat sektöründe olumlu gelişmeye neden olarak endüstriye kazandırılabilir. Bu atık maddelerin faydalı geri dönüşüm mekanizmaları ile tekrar kullanılması hem çevresel korunum hem de ekonomik kazanım yönünden çok büyük öneme sahiptir.

\section{TEŞEKKÜR}

$\mathrm{Bu}$ çalışmada laboratuvar imkanlarını kullandığımız Niğde Ömer Halisdemir Üniversitesi Endüstriyel Hammaddeler ve Yapı Malzemesi Uygulama Araştırma Merkezi (NÜHAM)'ne teşekkür ederiz.

\section{KAYNAKLAR}

[1] GÖKÇE, M.V., "Diyatomit Esaslı Hafif Yapı Elemanı Üretiminde Üre-Formaldehitin Bağlayııı Olarak Kullanılması", Doktora Tezi, Selçuk Üniversitesi, 2010.

[2] Bİlgíl, A., YEŞILluURT, E., GÖKÇE, M.V., "Production of Pumice-Based Geo-Polymer Concrete", Proceedings of the International Conference on Civil and Environmental Engineering, 1608-1614. Nevşehir, Türkiye, 2015.

[3] ÜNAL, O., ERGÜN, A., UYGUNOĞLU, T., KÜRKLÜ, G., Hafif Agregalı Blok Elemanların FizikoMekanik Özelliklerinin Araştırılması ve Modellenmesi, TÜBİTAK Proje No: 104M391, 2008.

[4] http://pomza.com.tr (erişim tarihi: 23.06.2018)

[5] DOĞAN-SAĞLAMTIMUR, N., Bİlgíl, A., DEMIR, M., YILMAZ, M.L., POLAT, S., ÖZEN, E., DÖRDÜ, H., "A Reuse Study from Niğde, Turkey: The Conversion of Industrial Ash to Geopolymer", Desalination and Water Treatment, 57, 2604-2615, 2016a.

[6] DOĞAN-SAĞLAMTIMUR, N., Bİlgill, A., CİlA, T., DURSUN, M., YILDIRIM, G., AKBULUT, H., DOĞUÇ, Ü., ERKEKLİ, K., YILDIRIM, S., "Göknur A.Ş. Niğde Fabrikası Kazan Altı Küllerinden Çimento Bağlayıcılı Hafif Yapı Elemanı Üretimi”, Çevre Bilim ve Teknoloji, 1, 50-57, 2016 b.

[7] YÜKSEL, İ., ÖZKAN, Ö., BİLİR, T., "Kazanaltı Külü ile Briket Üretimi”, Gazi Üniversitesi Mühendislik Mimarlık Fakültesi Dergisi, 21, 527-532, 2006.

[8] DOĞAN-SAĞLAMTIMUR, N., GÜVEN, A., BİlgİL, A., "Physical and Mechanical Properties of New Produced Cemented Ash-Based Lightweight Building Materials with and without Pumice", Advances in Materials Science and Engineering, 2018, 1-12, 2018.

[9] FINDIK, H., "Termik Santrallerde Çevresel Maliyetlerin Muhasebeleştirilmesi”, Gaziantep University Journal of Social Sciences, 14, 781-796, 2015.

[10] SIDDIQUE, R., "Utilization of Coal Combustion By-Products in Sustainable Construction Materials", Resources, Conservation and Recycling, 54, 1060-1066, 2010.

[11] JAYARANJAN, M.L.D., VAN HULLEBUSCH, E.D., ANNACHHATRE, A.P., "Reuse Options for Coal Fired Power Plant Bottom Ash and Fly Ash", Reviews in Environmental Science and Bio/Technology, 13, 467-486, 2014.

[12] ÖZKAN, Ş.G., TUNCER, G., "Pomza Madenciliğine Genel Bir Bakış", 4. Endüstriyel Hammaddeler Sempozyumu, 200-207, İzmir, Türkiye, 2001.

[13] BELLİ, O., Tarih Boyunca Van, Nadir Kitap, İstanbul, Türkiye, 2007.

[14] DEMIR, İ., BAŞPINAR, M.S., GÖRHAN, G., KAHRAMAN, E., AKYOL, O., "Pomza Agregalı Hafif Beton Isıl Özelliklerine Polistiren Köpük ve Uçucu Kül Katkısını Etkileri”, X. Ulusal Tesisat Mühendisliği Kongresi, 911-916, İzmir, Türkiye, 2011.

[15] BAI, Y., DARCY, F., BASHEER, P.A.M., "Strength and Drying Shrinkage Properties of Concrete Containing Furnace Bottom Ash as Fine Aggregate", Construction and Building Materials, 19, 691-697, 2005.

[16] YÜKSEL, İ., BİLİ, T., ÖZKAN, Ö., "Durability of Concrete incorporating Non-Ground Blast Furnace Slag and Bottom Ash as Fine Aggregate", Building and Environment, 42, 2651-2659, 2007.

[17] NATARAJ, K., MIDUN, S.M., HARI, K.M., GANESH, G.M., SANTHI, A.S., "Bottom Ash Concrete", International Journal of Advanced Research in Mechanical and Production Engineering and Development, 1, 6-11, 2013.

[18] WONGKEO, W., CHAIPANICH, A., "Compressive Strength, Microstructure and Thermal Analysis of Autoclaved and Air Cured Structural Lightweight Concrete made with Coal Bottom Ash and Silica Fume”, Materials Science and Engineering: A, 527, 3676-3684, 2010. 
[19] YADOLlAHI, M.M., VAROLGÜNEŞ, S., İŞSEVER, F., "Na르, Silika Modülü, Su/Bağlayıcı Oranı ve Yaşlanmanın Cüruf Tabanlı Geopolimerlerin Basınç Mukavemetinde Olan Etkileri”, Türk Doğa ve Fen Dergisi, 6, 26-31, 2017.

[20] JUSTNES, H., MARTIUS-HAMMER, T.A., "Sürdürülebilirlik-Beton İnovasyonundaki Öncü Rolü”, Hazır Beton, 23, 77-82, 2016.

[21] SALAHUDDIN, M.B.M., NORKHAIRUNNISA, M., MUSTAPHA, F., "A Review on Thermophysical Evaluation of Alkali-Activated Geopolymers", Ceramics International 41, 4273-4281, 2015.

[22] DAVIDOVITS, J., "Geopolymer Chemistry and Sustainable Development", Proceedings of the World Congress Geopolymer, 9-15, Saint-Quentin, France, 2005.

[23] KAYA, M., UYSAL, M., YILMAZ, K., "Jeopolimer harçlarda dayanım, kür sıcaklığı ve boşluk oranı ilişkisinin varyans analizi ile incelenmesi”, Sakarya Üniversitesi Fen Bilimleri Enstitüsü Dergisi, 22, 248$256,2018$.

[24] TOPÇU İ.B., TOPRAK, M.U., “Alkalilerle Aktive Edilen Taban Küllü Hafif Harç Üretimi”, Eskişehir Osmangazi Üniversitesi Mühendislik Mimarlık Fakültesi Dergisi, 2, 153-164, 2009.

[25] BİDECİ, A., GÜlTEKIN, A.H., YILDIRIM, H., OYMAEL, S., ANDBİDECI, O.S., "Internal Structure Examination of Lighweight Concrete Produced with Polymer-Coated Pumice Aggregate", Composites: Part B, 54, 439-447, 2013.

[26] BİDECİ, Ö.S., BİDECİ, A., GÜLTEKİN, A.H., OYMAEL, S., YILDIRIM, H., "Polymer Coated Pumice Aggregates and Their Properties", Composites: Part B, 67, 239-243, 2014.

[27] YAZICI, H., "Yapay Alçı-Uçucu Kül Esaslı Bağlayıcıların Mekanik Özellikleri”, DEÜ Mühendislik Fakültesi Fen ve Mühendislik Dergisi, 7, 65-72, 2005.

[28] http://www.intes.org.tr/content/MArt-2014.pdf (erişim tarihi 23.06.2018)

[29] https://intweb.tse.org.tr/standard/standard/Standard.aspx?0811180511151080511041191101040550471051 02120088111043113104073090097085121057113053070083067073 (erişim tarihi: 23.06.2018)

[30] BİNİCI, H., EKEN, M., AKSOĞAN, O., "Cüruf, Uçucu Kül, Silis Kumu ve Pomza Esaslı Geopolimerlerin Fiziksel, Mekanik ve Radyasyon Geçirgenlik Özellikleri”, Yapı Teknolojileri Elektronik Dergisi, 8, 2012.

[31] TOP, S., VAPUR, H., "Effect of Basaltic Pumice Aggregate Addition on the Material Properties of Fly Ash Based Lightweight Geopolymer Concrete", Journal of Molecular Structure, 1163, 10-17, 2018. 